International Journal of Research in Engineering and Innovation
(IJREI)
journal home page: http://www.ijrei.com

\title{
Review on spectroscopic analytical methods for determination of metformin hydrochloride
}

\author{
Nisreen Kais Abood ${ }^{1}$, Dalia Mahmood², Amina M.Abass² \\ ${ }^{1}$ Department of Chemistry, College of Science, Mustansiriyah University Baghdad, Iraq \\ ${ }^{2}$ Department of Chemistry, College of Science, Al-Nahrain University, Al-Jaderia, Baghdad-Iraq
}

\begin{abstract}
Simple sensitive methods to estimate the metformin hydrochloride. It works to reduce blood glucose level in NIDDM patients. Metformin is a biguanide anti hyperglycemic agent. It works by decreasing glucose production by the liver and increasing the insulin sensitivity of body tissues. Literature survey reveals analytical methods such as UV Spectrophotometry, liquid chromatography, gas chromatography, GC-MS , flow injection fluorescence and flow injection MS/MS, have been reported for estimation of the metformin hydrochloride in pharmaceutical formulations and biological fluids. (C2020 ijrei.com. All rights reserved
\end{abstract}

Keywords: Metformin, Analytical methods, liquid chromatography

\section{Introduction}

Metformin hydrochloride, chemically 1, 1-dimethyl biguanide hydrochloride is a white crystalline powder, hygroscopic and freely soluble in water, used as a hypoglycemic drug: molecular formula $\mathrm{C}_{4} \mathrm{H}_{11} \mathrm{~N}_{5}$.HCL [1-2] structural formula of metformin drug show in figure 1 . The name "Metformin" is the BAN, USAN and INN for the medication. It is offered beneath a number of trade names, which include Glucophage XR, Carbophage SR, Riomet, Fortamet, Glumetza, Obimet, Gluformin, Dianben, Diabex, Diaformin, Siofor, Metfogamma and Glifor. It is used as an antihyperglycemic (antihyperglycemic) and for the treatment of kind 2 diabetes according to the World Health Organization (WHO) which often influences those over the age of forty years as properly as in addition to extraordinary age agencies induced by insulin deficiency due to the presence of weakness in the beta cells) in The pancreas, which secretes insulin or as an end result of the introduction of sites in the body, or because of insufficient resistance to insulin receptors, especially in humans with weight problems [3-7] considering it works to counter insulin resistance, in particular in the liver and skeletal muscles, and increases the sensitivity of the insulin surrounding in some tissues Like muscles, and tissues Lipomas works on the oxidation of fatty acids and promotes decomposition of peripheral glucose [8-10]. Metformin was once first synthesized in the 1920, because of a want for a drug that diminished blood sugar levels. After that, he disregarded this drug for two decades, with research pastime in insulin and other anti-diabetic drugs. Then manufacturing of metformin flourished in late 1940, after various reports proved that it may want to lead to low blood sugar. In 1957, the French medical doctor Jean Stern, published the first clinical trial of metformin as a therapy for diabetics. It was produced in the United Kingdom in 1958, in Canada in 1972, and in the United States in 1995, and it is believed to be the most extensively prescribed medication in the world. [11-12].

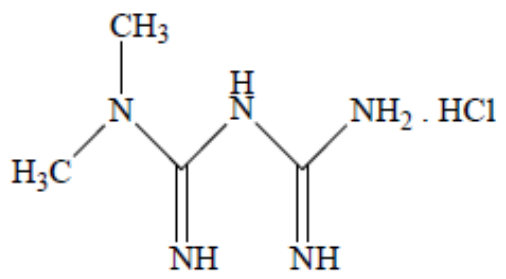

Figure 1: structural formula of metformin drug

\subsection{Physical properties of the drug}

- Solid in standard conditions STP

- Melting point m.p5224.5

- Refractivity. 56.642 
- Polarize ability 13.42

- Molecular Weight (165.6gm / mol). [13-14].

\subsection{Side effect of metformin}

- metallic taste in the mouth

- diarrhea

- nausea of vomiting

- swelling

- Double the appetite

- fast heart rate

- Headache

- It may cause anemia or cause a decrease in the absorption of vitamin $\mathrm{B}_{12}$.

- It also causes a condition called Lactic acid [15-17]

\subsection{Metformin Bioavailability}

Bioavailability of metformin is confined to (50-60\%) and is in the main absorbed in the small intestine. The concentration of the drug has been determined in the plasma up to a maximum of two hours after taking the dose by using mouth, and that the drug accumulates in the partitions of the intestine and small salivary glands as properly as in the kidneys. [18-19]

\subsection{Metformin use as chelating complex}

Metformin possesses two organizations of amines at the site (cis) and thus acts as a clinked, and this makes it an great capability to shape coordination complexes with specific transition metallic ions the place metformin can bind to the transition steel ions either via the 0.33 nitrogen atom $\left(\mathrm{N}_{3}\right)$ or from $\mathrm{By}$ the $2 \mathrm{~d}$ and fourth nitrogen atoms $\left(\mathrm{N}_{2}-\mathrm{N}_{4}\right)$ [20-23], metformin coordinates with the a number of ions of the transition elements and gives chelating complexes of unique colors, mainly with the following transitional elements] Cu (II), Ni (II), Co (II), Pt (II) [24] . Fig.2 shows the reaction of consistency of metformin with Biting transition metal ions.

\subsection{Previous studies to estimate metformin}

There are several methods used to estimate metformin in pharmaceutical preparations and in serum samples in addition to multiple environmental models. These spectroscopic, chromatographic and physical methods and table (1) show the estimation of metformin with different techniques.
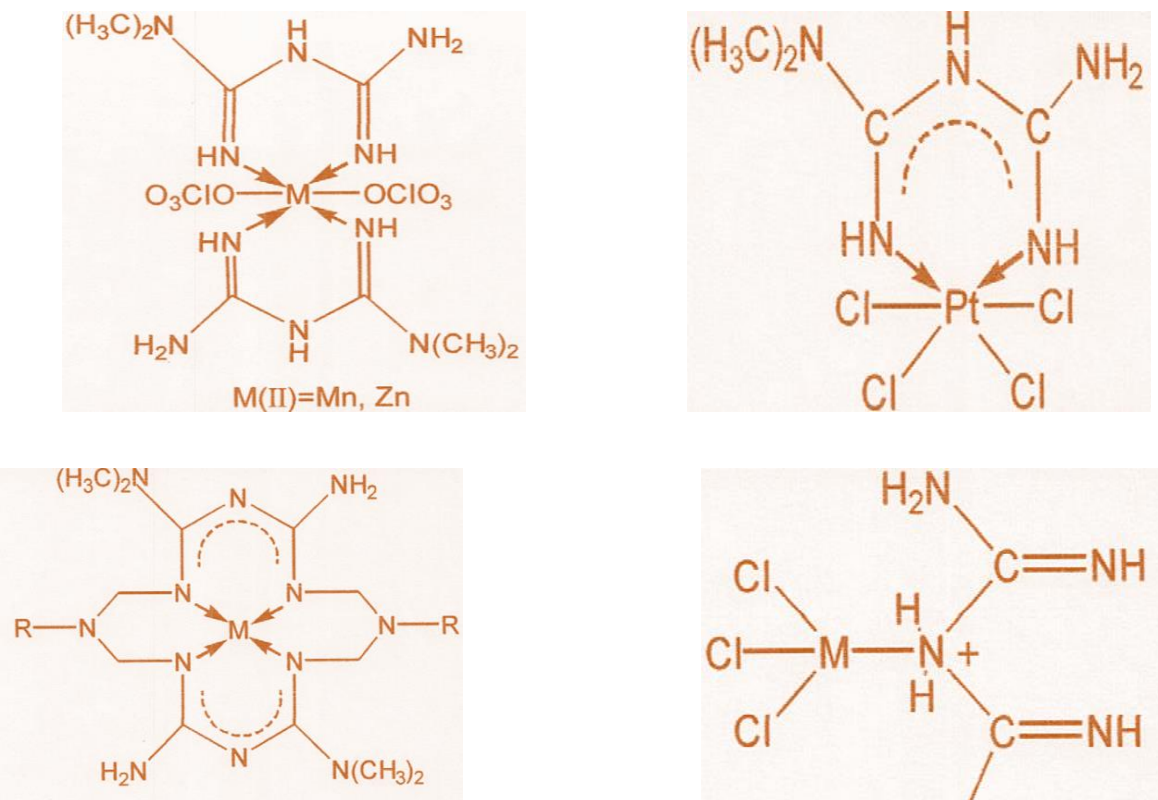

$\mathrm{ML}: \mathrm{M}(\mathrm{II})=\mathrm{Ni}, \mathrm{Cu} ; \mathrm{R}=\mathrm{H}, \mathrm{NH}_{2}$ or $\mathrm{ML} \cdot 3 \mathrm{H}_{2} \mathrm{O}: \mathrm{M}(\mathrm{II})=\mathrm{Cu} ; \mathrm{R}=\mathrm{NH}_{2}$
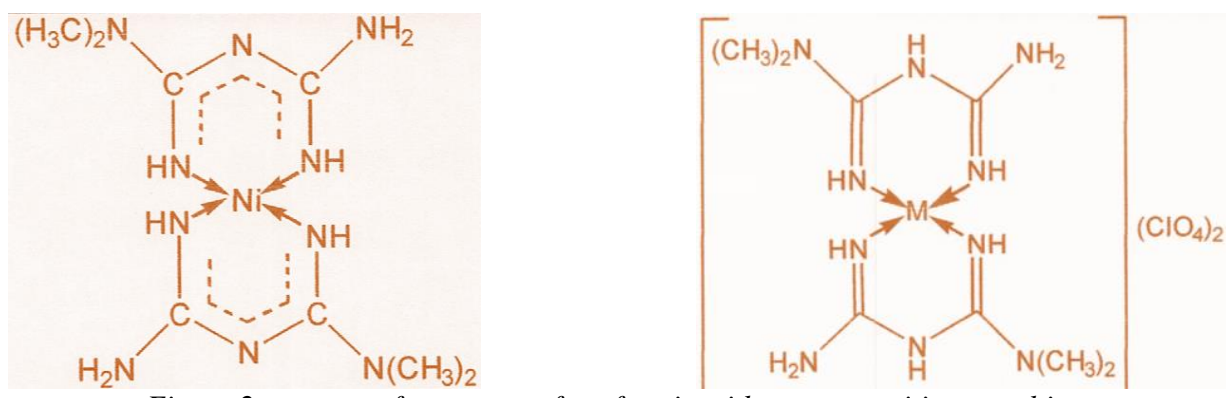

Figure 2: process of symmetry of metformin with some transition metal ions 
Table 1: Estimation of metformin hydrochloride drug with different techniques

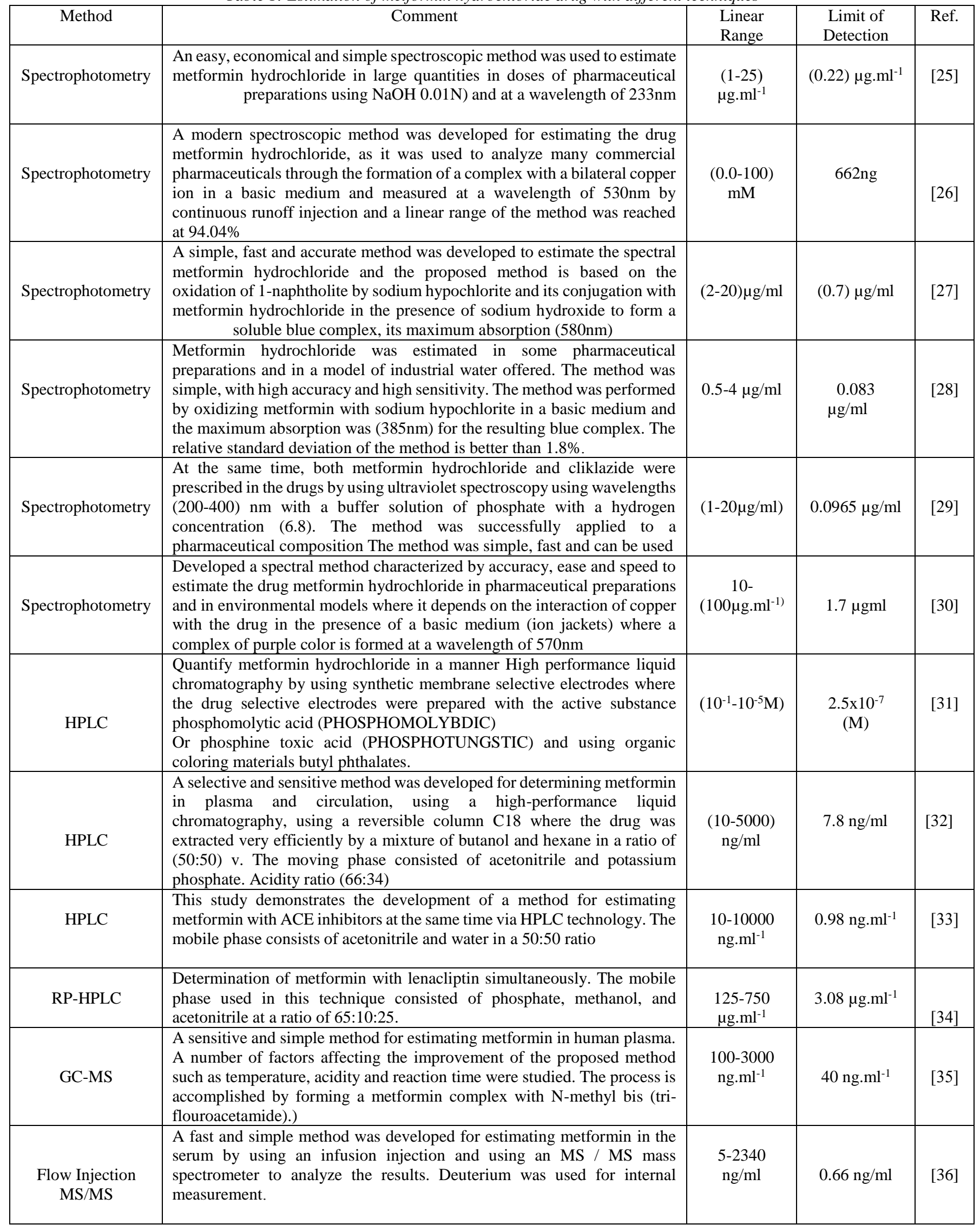




\begin{tabular}{|c|c|c|c|c|}
\hline Flow Injection & $\begin{array}{l}\text { The development of a rapid and sensitive analytical method for estimating } \\
\text { metformin by means of a complex formation of a system: metformin- } \\
\text { sodium hydroxide - copper ion (II) contained within the gel and using the } \\
\text { infusion system. The method was based on a complex composition between } \\
\text { the displaced copper ion of the gel and the metformin drug in a basal } \\
\text { medium a reddish-burgundy color which is absorbed at 530nm. }\end{array}$ & $\begin{array}{l}(0.001-1) \\
\text { mmol.L-1 }\end{array}$ & $0.5 \mu \mathrm{mol} . \mathrm{L}^{-1}$ & [37] \\
\hline Flow Injection & $\begin{array}{l}\text { Determination of metformin in pharmaceutical preparations and biological } \\
\text { fluids by means of } \beta \text {-cyclo dextrins sensors. The manufactured electrodes } \\
\text { contain the sensor ion holder, ionic sites and plastic materials in addition to } \\
\text { the coated wire electrodes. One of the advantages of this method is that } 90 \\
\text { samples can be analyzed in a simple and sensitive }\end{array}$ & $\left(10^{-1}-10^{-6}\right) \mathrm{M}$ & $8 \times 10^{-7} \mathrm{M}$ & [38] \\
\hline $\begin{array}{l}\text { Flow Injection } \\
\text { Fluorescence }\end{array}$ & $\begin{array}{l}\text { This method is based on (CL) chemiluminescence of chemical fluorescence } \\
\text { by oxidizing N-bromo succinic imide in an alkaline medium with the } \\
\text { presence of a fluorescence process and using an acetylcholine such as } \\
\text { ammonium bromide. }\end{array}$ & $\begin{array}{l}\left(7 \times 10^{-9}\right. \\
\left.3 \times 10^{-5}\right) \\
\text { g. } \mathrm{ml}^{-1}\end{array}$ & $2.3 \times 10^{-9} \mathrm{~g} \cdot \mathrm{ml}^{-}$ & [39] \\
\hline
\end{tabular}

\section{Conclusions}

In this review different methods for estimation of metformin hydrochloride for pharmaceutical preparation and wide range of the instrumental technique to estimation most of these methods are time consume and complex. All instrumental methods to determination metformin hydrochloride provide the simplicity, sensitivity, low detection limit, accuracy, rapid analysis and economical methods analytical to estimation this drug.

\section{References}

[1] Wang. Y, Tang. Y, Fawcett. JP, and Bai. X, " Rapid and sensitive liquid chromatography-tandem mass spectrometric method for quantitation of Metformin in human plasma", J chromatography B., 808, 9-215, (2004).

[2] Lalhriatpuii. T, Kawathekar. N, "Derivative spectrophotometric estimation of pioglitazone and metformin hydrochloride", Indian Drugs. ; 42(11):7403, (2005).

[3] R. Nelson, D. Spann, D. Elliott, A. Bronds, and R. Vuliet, "J. of veterinary inter. Med. ,18,8-24, (2004)

[4] Prachi. S, Ajay. S, R, Nilesh. G, "UV Spectrophotometric method for the quantitation of metformin hydrochloride in pharmaceutical dosage form", Oriental J. Of Chem., 4, 1553-1556, (2010).

[5] Gusler. G, Gorsline. J, Zhang. S, Berner. B," Pharmacokinetics of metformin gastric-retentive tablets in healthy volunteers", J. of clin. Pharmacology, 41, 655-661, (2001).

[6] S. Wang, H. Kusuhara, Y. Kato, W. Jonker, and Y, "Involvement of organic cation transporter 1 in the lactic acidosis caused by metformin ", Molecular pharmacology, 16(4), 8-844, ( 2003).

[7] Dorman. T, "Double-blind evaluation of efficacy and tolerability to metformin in NIDDM ", Diabetes care, 14, 342-344, (1991).

[8] Stepensky. D, Friedman. M, Srour. W, Raz. I, Hoffman. A, "Preclinical evaluation of pharmacokinetic-pharmacodynamic rationale for oral CR metformin formulation", J. control Realease , 71, 107-117, (2001).

[9] Arayne MS, Sultana N, Zuberi. MH and siddiqui. FA, "Spectrophotometric quantitation of Metformin in bulk drug and pharmaceutical formulation using multivariate technique"; india J. pharma, 71,331-335, (2009).

[10] Agarawal. Y. K, Gogoi. P. J, Manna. K, Bhatt. H. G, "Supercritical fluid Chromatography tandem mass spectrometry method for the simultaneous quantification of metformin and glicaside in human plasma", Indian $\mathrm{j}$. pharma, 72, 7-50, (2010).

[11] Bailey. CJ, Day. C, "Metformin its botanical Background", John wiley\&Sons, Ltd, 115-117, (2009).

[12] The use of Medicines in the United States: Review of 2010, institute for health care informatics, (2011).

[13] Vogel's Text book of Quantitative chemical Analysis, 6th Ed PeaarsEdu Itd, Singapor, (1989).

[14] The council of the Royal pharmaceutical society of Great Britain, The Extra pharmacopoeia, published by Royal pharmaceutical society, UK, 357, (2005).
[15] Bodmer. M, Meier. C, Jick. SS, " Metformin sulfonylureas or other antidiabetes drugs and the risk of lactic acidosis or hypoglycemia: a nested case-control analysis"; Diabetes care, 31, 2086-2091, (2008).

[16] Rossing. P, Rossing. K, Gaede. P, Pederson. O, Parving. HH, "Monitoring Kidney function in type 2 diabetic patients with incipient and overt diabetic nephropathy", Diabetes care, 29, 1024-1030, (2006).

[17] Jolien. D. J, Andrian. K, Ab. M. J. Donker, Michiel. G. W, "Long term treatment with metformin in patients with type 2 diabetes and risk of vitamin B-12 deficiency: Randomised placebo controlled trial", BMJ (2010).

[18] Wilcock. C, Bailey. CJ, "Accumulation of metformin by tissues of the normal and diabetic mouse", Xenobiotica; 24: 49-57, (1994).

[19] Scheen. AJ, "Clinical pharmacokinetics of metformin", Clin Pharmacokinet, 30: 359-371, (1996).

[20] Bentefrilt. F, Morgent. G, Viossat. B, Leonce. S, J. Inorg. Biochem 68, p: 53-59, (1997).

[21] Gowdhury. S. R, Sipani. M. K, J. Indian chem., 65, 718, (1988).

[22] Miaoli. Z, Liping. L, Pin. Y, Xianglin. J, "Bis (1,1-dimethyl biguanido) nickel(II)" ; Acta Cry. , 58, p: 272, (2002).

[23] Olar. R, Badea. M, Marineescu. D, Chifiriue. M, "displaying low cytotoxicity as potential large spectrum antimicrobial agents"; N, Ndimethyl biguanide complexes displaying low cytotoxicity as potential large spectrum antimicrobial agents", Eur. J. Med. Chem., 45, 3027-3034, (2010).

[24] Tomas. A, Viossat. B, Dung. N. H," L' hydrogenocarbonate de Bis(N,Ndimethyl biguanide ) Cuivre(II) ", Acta. Cryst, 51, 213-215, (1995).

[25] Reatul. K, Nurunnahar. P, Rebecca. B, "Development and validation of UV spectroscopic method for the determination of metformin hydrochloride in tablet dosage from", International J. Ph. Sci. and Res., 3(9), 3170-3174, (2012).

[26] Issam. M. A, Basim. I, Huda. M. N, "Continuous Flow injection Analysis (CFIA) of Metformin Hydrochloride using Microphotmeter Equipped with 530 and 550nm LED", J. of Al-Nahrain Uni. , 16(4), 29-36, (2013).

[27] Nief. R. A, Farah. K. O, "Spectrophotometric determination of metformin hydrochloride via oxidative coupling reaction with 1-naphthol in pharmaceutical and environmental water sample", Iraq National J. of chem. ; 46, 161-170, (2012).

[28] Nief. R. A, "Facial visible spectrophotometric determination of metformin hydrochloride in glucosam and industrial waste: Application to content uniformity testing", Iraq pharma; 12, No.1, (2012).

[29] Radhika. B, Rahul. B, Mahendra. K. S, Vipin, "Uv-SpectrophotometricAssisted of metformin hydrochloride and Gliclazide in pharmaceutical formulations"; ph. Anal. Acta, 2153-2435, (2012).

[30] Nief. R. A, "Spectrophotometric determination of metformin in pharmaceutical preparation (tablets) and environmental water samples: Application to content uniformity testing"; Iraq National J. of chem., 47, 300-310, (2012).

[31] Ali I. Khaleel ,Suham T. Amine and Emad M. Yousif' Determination of Metformine Hydrochloride Drug by Using of Manufactured Selective Membrane Electrodes and High Performance Liquid Chromatography Method HPLC” Raf. J. Sci., Vol. 21, No.3, pp. 138-157, (2010).

[32] Raniah Q.G, and Raj S.P., "Determination of Metformin in Human Plasma and Urine by High - Performance Liquid Chromatography Using Small Sample Volume and Conventional Qctadecyl Silane Column", J. Ph. Pharmaceut, 13(4), 486-494, (2010). 
[33] Farhan. A. S, Nawab. S, Saima. S. B, Concurrent determination of metformin and some ACE inhibitors: its application to pharmacokinetics, 2013

[34] Sheena. M, Rohini. R, "Simultaneous determination of metformin hydrochloride and linagliptin by RP-HPLC in bulk and pharmaceutical formulation", Indo Amer. J. of pharm. Reas., 4, 4047-4053, ( 2014).

[35] Ebru. U, "The development and validation of gas chromatography-mass spectrometry method for the determination of metformin in human plasma" Royal soci. Chem., 5, 4723-4730, (2013).

[36] Deborah. M, Terra. A, Anas . EL, "Development and validation of fast and simple Flow injection Analysis- tandem mass spectrometry (FIA-MS/MS) for the determination of metformin in dog serum ", J. of ph. and Biom. Anal. ; 107, 229-235, (2015).
[37] Issam. M. A, Nagam. S. T, "Continuous Flow Injaction Analysis for the photometric determination of metformin drug via the realese of copper (II) ion from charged Gel bead crystal", Iraq J. of sci., 54, 17-26, (2013).

[38] Khaled. E, Kamel. MS, Hassan. HN, Abd El-Alim. SH. Enein. HY, Miniaturized ionophore-based potentiometric sensors for the flow-injection determination for metformin in pharmaceutical formulations and biological fluids", National institutes of health, 137(23), 7-5680, (2012).

[39] Zhouping. W, Zhujum. Z, Zhifeng. Fu, Wanfem. L, Xiao. Z, "Sensitive Flow-injection chemiluminescence determination of metformin based on $\mathrm{N}$ Bromosuccinimide-fluorescein system", J. Anal. Letters-Anal let, 36, 2683 2697, (2003).

Cite this article as: Nisreen Kais Abood, Dalia Mahmood, Amina M.Abass, Review on spectroscopic analytical methods for determination of metformin hydrochloride, International Journal of Research in Engineering and Innovation Vol-4, Issue-2 (2020), 9195. https://doi.org/10.36037/IJREI.2020.4203. 